\title{
Implicit Beliefs about Self and Nature: Evidence from an IAT Game
}

\author{
Coral M. Bruni*, P. Wesley Schultz California State University, San Marcos, CA, United States
}

\begin{abstract}
Recent psychological research has examined the beliefs that individuals hold about their relationship with the natural world. This article builds on the previous literature on connectedness with nature and we introduce a new game version of the Implicit Association Test (IAT), known as FlexiTwins. The game is intended to facilitate research using the IAT and provides a flexible platform for measuring implicit associations. In this paper, we report three studies in which we use the game to measure self-nature associations. Study 1 reports the development and validation of FlexiTwins with a college sample. Study 2 further validates the game using a known-groups sample of environmental activists. Finally, Study 3 examines the implicit connectedness of a sample of 30 grade school children. Across all three studies, we find good evidence for reliability, as well as theoretically meaningful results.
\end{abstract}

\section{Introduction}

There is a growing body of psychological research examining an individual's beliefs about the degree to which he or she is part of the natural environment. Theoretically, this sense of connectedness provides a foundation for the types of environmental attitudes that a person will hold, his or her concerns about environmental problems, and his or her decisions to engage in proenvironmental behavior. Previous studies have referred to this sense of connect- edness as “'primitive,' “'zero-order,'” and “'implicit,' and a variety of tools have been developed to measure these beliefs (Schultz, 2002; Schultz, Shiver, Tabanico, \& Khazian, 2004). One measurement approach involves the use of the Implicit Association Test (IAT) and several studies have been reported in which the IAT was used to assess a person's implicit associations between " self"' and " "nature." However, because of the technology required to measure implicit beliefs, studies in this area are typically confined to controlled laboratory environments and the approach does not lend itself to field research, nor to real-world samples. The current article pres- ents a new game interface for measuring implicit associations. Three studies are reported in which we use the game interface to examine the experiential, attitudinal, and behavioral correlates of implicit connectedness with nature.

Psychological research on environmental issues has been well-underway for more than 40 years. During most of this time, theoretical models and principles have been drawn extensively from social psychology.

* Corresponding author. Department of Psychology, California State University, San Marcos, CA 92096, United States. Tel.: p1 7607165361.

E-mail address: cbruni@csusm.edu (C.M. Bruni). 
Constructs borrowed from social psychology include attitude theory (in its many forms), values, persuasion, risk communication, and norm activation, to name a few. Yet recently, theoretical models and constructs of environ- mental attitudes and behavior are emerging that are unique to this area of research. One such construct is connectedness with nature. In conceptual terms, connectedness is the degree to which an individual believes that he or she is part of the natural environment (Schultz, 2000, 2002). While such beliefs (and related constructs) have appeared in the philosophical, sociological, anthropological, and historical literature for many years, they have only recently begun to be explicated by behavioral scientists (e.g., Arnocky, Stroink, \& De Cicco, 2007; Dunlap, Van Liere, Mertig, \& Jones, 2000; Dutcher, Finley, \& Luloff, 2007; Kidner, 2001; Rolston, 1988).

From a psychological perspective, several paper-and-pencil measures of connectedness with nature have been developed (e.g., Mayer \& Frantz, 2004; Pennisi, 2007; Schultz, 2002), as have scales for measuring the related construct of environmental identity (e.g., Clayton, 2003). All of these measures rely on self-report responses, which may pose a problem in examining connectedness with nature. First, there is a strong social desirability element with the explicit measures which may artificially increase the mean scores or decrease the range and variability of responses. Furthermore, several authors have suggested that these beliefs about connectedness with nature are “'zero-order”' beliefs (Dunlap et al., 2000), and outside of our s ense of selfawareness (Frantz, Mayer, Norton, \& Rock, 2005), in which case they might not lend themselves to conscious elaboration and self-report (Schultz et al., 2004). With these limitations in mind, researchers have pursued implicit measurement techniques in the study of connectedness, with some interesting results.

The implicit measurement approach is based on recent developments in social cognition, and it measures the strength of association between the concept (natural versus built environments) and self (me versus not me). The emerging paradigm in social psychological research distinguishes between implicit and explicit attitudes (and cognition) and has sparked considerable interest and debate (Greenwald, McGhee, \& Schwartz, 1998; Greenwald, Nosek, \& Banaji, 2003; Nosek \& Smyth, 2007; Olson, Fazio, \& Hermann, 2007). The approach has been used to study implicit selfesteem (self-valence associations), self-concept (self- attribute associations), and attitudes (attribute-valence associations; Greenwald et al., 2002). Our interest here is in implicit selfconcept (see Perkins \& Forehand, 2006).

Using the Implicit Association Test (IAT), Schultz et al. (2004) examined the relationship between implicit connectedness with nature and explicit attitudes of concern about environmental problems. The results showed that stronger implicit connectedness with nature were positively correlated with biospheric concerns and negatively correlated with egoistic concerns, as measured using the environmental motives scale. In addition, when looking at the psychometric properties of the IAT used to measure implicit connectedness with nature, Schultz et al. (2004) found evidence for the reliability of this measure using test-retest: immediately $(r=.45)$, after one-week $(r$ $=.46)$, and after four-weeks $(r=.40)$. While these test-retest correlations are low by traditional standards, Rosenthal and Rosnow (1984, p. 50) suggest that acceptable test-retest reliabilities "'depend on the situation and the nature of the variable being measured." Given that the IAT makes use of reaction time - a metric notorious for its high degree of variability and sensitivity to "noise" - allowing for lower levels of reliability seems warranted (see also Cunningham, Preacher, \& Banaji, 2001). Indeed, in looking at the results from other studies using implicit measures, test-retest scores commonly range from .4 to .6. In a review of existing studies, Nosek, Greenwald, and Banaji (2007) report a median test-retest value of $r=.56$. 
Given the encouraging results from studies using implicit measures of connectedness with nature, researchers have proceeded to examine more substantive research topics and to develop conceptual frameworks around the general construct (Bruni, Frazer, \& Schultz, 2008). One line of work has examined the influence of context and experience on connectedness. If a person's sense of connectedness is indeed "zero-order" then it should not be particularly susceptible to change from context to context. In a set of six studies, Schultz and Tabanico (2007) developed and validated a Palm Pilot version of the IAT-nature and then used the Palm version to explore how connectedness with nature were affected by context. The results replicated the previous findings regarding the relation- ship between connectedness with nature and explicit environmental concerns and demonstrated that the IAT procedure can be utilized in a field context. Finally, the results showed that while the implicit connectedness scores were relatively stable, they were correlated with repeated visits to a natural area (San Diego Wild Animal Park, beach, and hiking trail; but not golf course, indoor rock climbing facility, library, exercise gym facility, or office environment).

The results to date regarding implicit connectedness with nature are encouraging and warrant continued exploration. However, the existing measurement procedures are cumbersome and are not easily implemented in contexts without specialized laboratory equipment or research software. In addition, prior research suggests that connectedness with nature develops at an early age and there are a number of important hypotheses to be tested about childhood experiences that lead children to develop (or lose) their sense of connection with the natural environment. But in our pilot testing using the traditional lab-based IAT, our child participants got bored with the procedure and we found it difficult to obtain usable data.

To facilitate the use of the implicit connectedness with nature measures (and implicit associations more broadly) in the field and with children, we integrated the basic IAT principles into a game interface. FlexiTwins is a game version of the IAT. It is based on the traditional IAT presented by Greenwald et al. (1998) with several modifications. First, FlexiTwins differs from the traditional IAT in that it is a colorful, animated game. In this computerized game version, two frogs are shown on lily pads, one on the left and one right side of the screen and background graphics show scenes from nature. FlexiTwins is similar to the traditional IAT in that stimuli are presented one at a time; however, unlike the traditional IAT wherein the stimuli are presented directly in the middle of the screen, the stimuli in FlexiTwins fall from the top to the bottom of the screen. FlexiTwins also uses sounds to provide feedback for correct and incorrect responses, which gives FlexiTwins a game- like feel that is not present in the traditional IAT. In addition, built in feedback reminders pop up on the screen, reminding participants to categorize stimuli as quickly and accurately as possible, high- lighting an aspect of the IAT important in gathering meaningful data. Participants receive points for their correct classifications and more points are awarded for faster responses. The game version was developed to be fun, attractive, and easily used with a wide range of ages. It provides scores pursuant to the improved scoring algorithm (Greenwald et al., 2003) and can be administered across a variety of platforms (e.g., PC, Internet, PocketPC). With these changes and modifications to the traditional IAT, FlexiTwins meets the needs of researchers in both the field and those working with children. ${ }^{1}$

The studies reported below were designed to examine the psychometric properties of the new FlexiTwins game interface and to examine the demographic, attitudinal, life experience, and behavioral correlates of implicit connectedness with nature.

${ }^{1}$ In addition to the data reported in this article, our research team conducted multiple laboratory studies during the development of the game. These data were used to refine the testing environment of the game and are available in the accompanying manual (Resume (www.csusm.edu/schultz)). In addition to our work on the FlexiTwins game reported here, we also developed an alternative game interface based on the principles of the Go-No-Go

Association Test (GNAT; Nosek \& Banaji, 2001). The data from this second measure failed to show a reasonable level of reliability, despite multiple modifications to administration and scoring, and it was subsequently dropped from future inquiry. For details on this alternative interface and research findings, see Resume 
(www.csusm.edu/schultz).

\section{Study 1: method}

\section{Overview}

Our first study examined the reliability and validity of our new measure, FlexiTwins, with a sample of college students.

\section{Participants}

Participants in the first study were 62 undergraduate university students (19 male and 42 female, 1 unknown). Participants were recruited from the Psychology Department's human participant pool. Place of residency of these students ranged from urban to rural, with $31 \%$ of participants living in urban areas, 57\% of participants living in suburban areas, and $11 \%$ of participants living in rural areas. This study was part of a larger study to validate both FlexiTwins and an alternative game version based on the Go-No-Go

Association Test. ${ }^{1}$

\section{Materials}

All materials were administered on the Internet at http://www.conservationpsychology.org/game. An online questionnaire was developed to measure explicit environmental concerns, demographic variables, and the FlexiTwins game was used to measure implicit connectedness with nature.

\section{Inclusion of nature in self}

This single-item graphical scale was used to measure the extent to which an individual includes nature within his or her cognitive representation of self. The modified scale contains a series of seven overlapping circles labeled "self'" and "nature"' and the item asks respondents to "Please circle the picture below that best describes your relationship with the natural environment. How inter- connected are you with nature?' Scores range from 1 to 7 , with the least overlapping circle receiving a score of 1 and the most over- lapping circle receiving a score of 7 . The circle with the least overlap represents an individual who views him or herself as separate from nature. The circle with complete overlap represents a person who views him or herself as the same as nature. Results from previous studies have found these responses to be positively correlated with self-reported environmental behavior, reliable across time in test- retest and correlated in hypothesized directions with measures of environmental concern (see Schultz, 2001, 2002).

\section{Personal environmental concern}

This single-item measure was taken from Dunlap, Gallup, and Gallup’s (1992, 1993) international public opinion poll. The item was used in the 1993 Health of the Planet study and has since been continued in public opinion polls of U.S. residents. This question measures a person's explicit account of their concern for environ- mental issues by asking them to rate how concerned they are personally about environmental problems. We used a scale from 0 (not at all concerned) to 10 (extremely concerned).

\section{Environmental motives scale}

This scale provides a measure of an individual's concern about environmental problems because of the consequences that result from harming nature. Concern for environmental issues is divided into three subscales: Egoistic concern, Altruistic concern, and Biospheric concern. Participants 
rated 12 items from 0 (not important) to 10 (supreme importance). Egoistic concern items were: me, my future, my lifestyle, and my health. Altruistic concern items were: future generations, my community, all people, and all children. Biospheric concern items were: plants, animals, marine life, and birds. Items were presented in a randomized sequence, and scores were produced by averaging the items within each of the three subscales and then mean-corrected by subtracting the grand mean of all 12 items for each person (see Milfont, Duckitt, \& Cameron, 2006; Schultz, 2000, 2001; Snelgar, 2006). Reliability analyses for these subscales, using Cronbach's alphas, were: Egoistic concern: $\alpha=.94$; Altruistic concern: $\alpha=.96$; Biospheric concern: $\alpha=.95$.

\section{Environmental intent}

Participants were asked to rate on a scale of 0 (Never) to 10 (Always) how often in their daily routine they considered the environmental impact of their actions. This new item was written to provide a general measure of environmental intention, rather than specific environmentally significant behaviors (see Stern, 2000).

\section{Environment or economic growth}

Participants were asked to choose between two statements about the environment and economic growth. The two statements were " protecting the environment should be given priority even if it causes slower economic growth and some loss of jobs" or "economic growth and creating jobs should be the top priority, even if the environment suffers to some extent." The item has been used by the Gallup polling organization for nearly 30 years (Saad, 2003).

\section{Demographics}

Demographic questions included gender, place of residency (urban, suburban, or rural), postal code, and time spent outdoors in the last week. In addition, participants were asked about the activities they did while outdoors (e.g., biking, camping, climbing). Finally, participants were asked to report the number of plants and animals that they personally cared for in their home.

\section{FlexiTwins}

The FlexiTwins game uses reaction time (in milliseconds) to measure the strength of associations between given categories. Means and standard deviations for compatible and incompatible blocks of trials are used to calculate a D-score showing the standardized strength of the relationship between categories and attributes (see Greenwald et al., 2002). To account for outliers and error, each response time per stimulus lower than $300 \mathrm{~ms}$ or higher than $1.5 \times T$ ( $T 1 / 4$ time in milliseconds for the stimulus to drop from top to bottom) was excluded from further analysis. This exclusion allowed us to control for participants being very fast or very slow, and to control for error. Calculations were made using data that encompasses the total time a stimulus was presented on the screen until a correct response was made, regardless of whether it was preceded by an incorrect response.

With the exception of the treatment of outliers described above, the D-score computations followed Greenwald et al. (2003) improved scoring algorithm. The D-score provides a numeric index of the degree to which each person associates "self' with " nature." While there is no absolute upper or lower limit, scores generally range from -2 to $\mathbf{p} 2$, indicating stronger associations with built or natural environments respectively. Scores of zero indicate no difference (i.e., an equal association strength between self-built and self-nature).

Like the traditional IAT procedure, FlexiTwins contains seven blocks (see Table 1 for a breakdown of the blocks and trials). In our studies, FlexiTwins was used to examine self-concept, 
or more specifically, self-attribute associations between the categories 'Nature' and 'Built'. To measure these associations, the participant's name was used as the 'Me' category, and a random list of other names was used as the 'Other' category. The stimuli for the built and nature categories were taken from previous work using the IAT-nature (Schultz \& Tabanico, 2007; Schultz et al., 2004). The following words were used as the stimuli for the built category: boat, car, chair, and truck. The following words were used as the stimuli for the nature category: tree, mountain, butterfly, and flower.

In the current study, stimuli were presented at the top of the screen and fell to the bottom of the screen. Stimulus fall duration was set to four seconds, with the stimulus resting at the bottom of the screen until correctly categorized. Immediately following the correct categorization of the stimulus the next stimulus appeared at the top of the screen for categorization. The game offers three background selections and in the current study the background was turned off, presenting a plain green background. Game sound and feedback reminders were turned on, which provided feedback for correct and incorrect responses.

Table 1

Breakdown of FlexiTwins blocks and trials.

\begin{tabular}{|c|c|c|c|}
\hline Block & Block type & Category & \# of trials \\
\hline 1 & Practice & 'Me' and 'Other' & 8 \\
\hline 2 & Practice & 'Nature' and 'Built' & 8 \\
\hline 3 & Compatible Test & $\begin{array}{l}\text { 'Nature/Me’ and } \\
\text { 'Built/Other' }\end{array}$ & 24 \\
\hline 4 & Compatible Test & $\begin{array}{l}\text { 'Nature/Me' and } \\
\text { 'Built/Other' }\end{array}$ & 48 \\
\hline 5 & Practice & 'Built' and 'Nature' & 8 \\
\hline 6 & $\begin{array}{l}\text { Incompatible } \\
\text { Test }\end{array}$ & $\begin{array}{l}\text { ‘Built/Me’ and } \\
\text { 'Nature/Other' }\end{array}$ & 24 \\
\hline 7 & $\begin{array}{l}\text { Incompatible } \\
\text { Test }\end{array}$ & $\begin{array}{l}\text { 'Built/Me' and } \\
\text { 'Nature/Other' }\end{array}$ & 48 \\
\hline
\end{tabular}

\section{Procedure}

After providing informed consent, participants completed the brief online questionnaire assessing their explicit environmental attitudes and beliefs, along with a few demographic questions. Following the questionnaire, participants completed FlexiTwins twice.

\section{Study 1: results and discussion}

Complete data were obtained from 62 participants, of whom 49 played FlexiTwins twice. No participants were removed from the data set due to high error rates. FlexiTwins D-scores at time 1 ranged from -.97 to $1.90(M=.44, S D=.45, N=62)$, and D-scores at the second administration ranged from -1.66 to $1.27(M=.38, S D=.52, N=49)$.

The hypothesis that FlexiTwins would be a reliable measure of implicit connectedness with nature was tested in two ways. First, we calculated a metric of internal consistency by correlating the two internal subscales (D1 and D2). D1 is computed using blocks 3 and 6; D2 is computed using blocks 4 and 7 (see Table 1$)$. Results showed that FlexiTwins D1 $(M=.47, S D=.60)$ was significantly correlated to FlexiTwins D2 $(M=.41, S D=.42), r=.58, p<.01$ at the first testing. At retest, FlexiTwins D1 $(M=.39, S D=.63)$ was also significantly correlated to FlexiTwins D2 $(M=$ 
$.37, S D=.48), r=.73, p<.01$. The reliability of the new measure was also assessed by examining the test-retest correlations of the D-scores across the two administrations, $r=.42, p<.01$.

Following our reliability analyses, we examined the correlations between implicit connectedness with nature and explicit measures of environmental concern (see Table 2). All correlations were conducted using the FlexiTwins $\mathrm{D}$-score from the initial testing $(N=62)$. FlexiTwins D-score was significantly correlated with the Personal Environmental Concern question $(M=6.09, S D=$ $2.14 ; r=.33, p<.05)$ and the Inclusion of Nature in Self measure $(M=3.61, S D=1.31 ; r=.30$, $p<.05)$. In addition, the FlexiTwins D- score was also found to be significantly correlated with responses to the Environmental Impact question $(M=5.66, S D=2.41 ; r=.29, p<.05)$. However, FlexiTwins D-score was not significantly correlated with the three subscales of the Environmental Motives scale, though the correlations were in the expected directions (Egoistic concern: $M=-$ $.29, S D=.76, r=-.18, p=.17$; Altruistic concern: $M=-.37, S D=.57, r=.00, p=.98$; and Biospheric concern: $M=.65, S D=1.09, r=.13, p=.34)$. Interestingly, we found that there was a significant difference in the FlexiTwins D-score of participants and their priorities of environmental protection versus economic growth, $t(58)=2.50, p<.05$. This difference shows that participants who reported that "protecting the environment should be given priority even if it causes slower economic growth and some loss of jobs”' $(M=.53, S D=.45, n=44)$ had higher D-scores than participants who endorsed "economic growth and creating jobs should be the top priority, even if the environment suffers to some extent”' $(M=.20, S D=.42, n=16)$.

We explored the relationship between implicit connectedness with nature and demographics of the participants. Surprisingly, only marginally significant gender differences were found in the FlexiTwins D-score between males $(M=.29, S D=.48)$ and females $(M=.50, S D=.44), t(59)=-1.17$, $p=.09$. However, the pattern was in line with past research, which has found that women tend to score higher than men on measures of implicit connectedness with nature (Schultz \& Tabanico, 2007). In addition, no significant correlations were found between the amount of time spent outdoors in the last week $\left(M_{\text {minutes }}=38.01, S D=31.97\right)$ and the FlexiTwins $\mathrm{D}$-score, $r=.10, p=.46$. 


\section{Study 2: method}

\section{Overview}

The findings from Study 1 suggest that FlexiTwins is a useful tool for measuring implicit connectedness with nature. The results from reliability analyses were in line with prior IAT studies and the pattern of correlations with other measures was consistent with our basic conceptual framework. In this second study, we collected data from a known group of environmentalists: staff at the World Wildlife Federation (WWF). We hypothesized that if FlexiTwins was a valid measure of implicit connectedness with nature, the D-scores of WWF participants would be overwhelmingly positive and significantly higher than D-scores from a sample of college students (and also higher than other previously-reported samples).

\section{Participants}

Participants were 129 employees of the World Wildlife Federation (WWF) United Kingdom office (39 male, 84 female, 6 unspecified). Participants were recruited through an internal email invitation and all measures were completed online. Place of residency of these employees ranged from urban to rural, with $19 \%$ of participants living in urban areas, $43 \%$ of participants living in suburban areas, and $33 \%$ of participants living in rural areas.

\section{Materials}

Materials used in this second study were similar to those used in Study 1. One difference between the two studies was the stimuli used for FlexiTwins game. For the Nature category, the stimuli used were: flower, mountain, tree, and waterfall. The stimuli used for the category Built were: car, chair, church, and truck. In our prior work, we have found that the specific stimuli do not exert a substantial effect on the resulting IAT scores (Schultz et al., 2005).

\section{Procedure}

Participants were instructed to visit http://www. conservationpsychology.org/game. After providing informed consent, participants completed the brief questionnaire assessing their explicit environmental attitudes and beliefs, along with a few demographic questions. After completing the questionnaire, participants played FlexiTwins. 


\begin{tabular}{|l|c|c|c|}
\hline & \multicolumn{2}{|c|}{ Implicit connections with nature (D-score) } \\
\hline & Study 1 & Study 2 & Study 3 \\
\hline $\begin{array}{l}\text { Personal } \\
\text { environmental } \\
\text { concern }\end{array}$ & $.33^{*}$ & .09 & .05 \\
\hline $\begin{array}{l}\text { Environmental } \\
\text { intent }\end{array}$ & $.29 *$ & -.02 & .12 \\
\hline EMS & & & \\
\hline Egoistic & -.18 & .07 & -.18 \\
\hline Altruistic & .00 & -.16 & .16 \\
\hline Biospheric & .13 & -.03 & -.02 \\
\hline INS & $.30 *$ & .01 & .23 \\
\hline
\end{tabular}

Note: INS = Inclusion of Nature in Self Scale; EMS = Environmental Motives Scale; $*$ significant at $p<.05$.

\section{Study 2: results and discussion}

Complete data was obtained from 129 participants. Three participants were removed from the data set due to excessive error rates (error rates $>30 \%$ ). D-scores on FlexiTwins ranged from -2.71 to $1.70(M=.62, S D=.58)$, indicating stronger associations with natural environments than built environments. The means for the implicit and explicit measures across all three studies reported in this manuscript are shown in Table 3.

Our first set of analyses examined the reliability of FlexiTwins. This analysis was conducted by examining the correlations between two subscales of the game (D1 and D2) and results showed that the D1 score $(M=.64, S D=.77)$ was significantly correlated to the D2 score $(M=.61, S D=$ $.53), r=.55, p<.01$.

Results showed no significant gender differences in implicit connectedness with nature between males $(M=.59, S D=.49)$ and females $(M=.65, S D=.58), t(120)=-.58, p=.56$.

Next, the correlations between explicit and implicit measures were assessed. Results showed no significant correlations between the implicit D-score and any of the explicit measures (Inclusion of Nature in Self: $M=4.77, S D=1.49, r=.01, p=.91$; Personal Environmental Concern: $M=$ 8.76, $S D=1.33, r=.09, p=.32$; Environmental Intent: $M=7.99, S D=1.79, r=-.02, p=.80$; subscales of Environmental Motives scale: Egoistic concern: $M=-1.14, S D=1.58, r=.07, p=$ .45; Altruistic concern: $M=.62, S D=.95, r=-.16, p=.08$; Biospheric concern: $M=.53, S D=$ 1.61, $r=-.03, p=.75)$.

The explicit attitudes of participants were examined next. When participants were asked how concerned they were about environmental problems using the personal concern question $(M=$ 8.76, $S D=1.33)$, the majority $(94 \%)$ answered that they were concerned about environmental problems, with approximately 85\% having extreme concern about environmental problems (8, 9, or 10 on an 11-point scale). For comparison, a 2001 public opinion poll con- ducted in England (DEFRA, 2002), found that among the generic public, only 35\% of the sample were " very concerned' ' (on a 5-point scale) about environmental problems.

In addition, when participants were explicitly asked about their connectedness with nature using the Inclusion of Nature in Self scale $(M=4.77, S D=1.49), 16 \%$ said they had no to slight connection with nature, $49 \%$ of participants said they had a strong connection with nature, with $19 \%$ of participants scoring 10 (completely connected with nature). For comparison, Schultz and Tabanico (2007) reported that the mean score on the connectedness with nature scale among 
American college students was 3.31 and slightly higher scores for a sample of visitors to the San Diego Zoo (M1/44.92 to 5.14 across three studies).

Table 3

Comparison of means across various studies.

\begin{tabular}{|c|c|c|c|c|c|c|c|}
\hline Sample & $\begin{array}{l}\text { D- } \\
\text { score }\end{array}$ & INS & EC & EI & Ego & Alt & Bio \\
\hline Study 1 : college students ( $N 1 / 462)$ & .44 & 3.61 & 6.09 & 5.66 & -.29 & -.37 & .65 \\
\hline Study $2:$ WWF-UK $(N 1 / 4$ 129) & .62 & 4.75 & 8.76 & 7.98 & -1.14 & .62 & .53 \\
\hline Study 3 : children ages $10-11$ ( $N$ 1/4 30) & .73 & 4.50 & 5.50 & 4.90 & -.16 & -.07 & .31 \\
\hline
\end{tabular}

Note: INS = Inclusion of Nature in Self measure (scores range from 1 to 7); WWF- UK = World Wildlife Fund UK; EC = Environmental Concern (scores range from 0 to 10); EI = Environmental Intent (scores range from 0 to 10); Ego = Egoistic concern; Alt = Altruistic concern; Bio = Biospheric concern (mean-corrected scores calculated using a 0-10 response scale in Studies 1 and 2 and a 1-7 response scale in Study 3). 
When participants were asked how often they considered the environmental impact of their actions $(M=7.98, S D=1.78), 4 \%$ said they did not consider the impact they had on the environment. However, results showed a high level of consideration, with $88 \%$ of participants saying that they did consider the impact they had on the environment (scores ranged from 7 to 10). This is higher than that found in Study 1 with a sample of American college students $(M=$ 5.66, $S D=2.41)$.

Finally, we asked WWF employees what should be given priority: economic growth or environmental protection. Of the 124 complete cases, 116 (90\%) chose environmental protection. For comparison, 69\% of our American college sample from Study 1 gave preference to environmental protection and 55\% of an English national sample rated environmental protection as more important than "'prices and jobs" (DEFRA, 2002).

Taken together, these findings suggest that a known group of environmentalists (employees from the WWF) showed high connectedness with nature, both implicitly and explicitly.

\section{Study 3: method}

\section{Overview}

Our third study was designed to examine the usefulness of FlexiTwins with a sample of children. Past research suggests that the IAT can be used with children as young as six (Baron \& Banaji, 2006); however, in our pilot research we found it difficult to obtain usable data from children younger than 12 .

\section{Participants}

Participants were 30 fifth grade children between the ages of 10-12 (16 boys and 14 girls) from a public elementary school in California. The children were randomly assigned to play FlexiTwins with either pictures or with words. Informed consent was obtained from the child's parent or legal guardian and informed assent was obtained from the child prior to participating in this study. These children are part of a larger study and the data served as a pilot test of materials to be used in an ongoing longitudinal study.

\section{Materials}

The measures used in this study were similar to those used in Study 2, with some minor modifications to make them more appropriate for use with children. One difference in this study was that in addition to a questionnaire, explicit attitudes were examined using a face-to-face interview with each child. This interview provided an opportunity to better understand the explicit environmental concerns of children using both a qualitative and quantitative method.

In addition to the interview, a few minor changes were made to the questionnaire. One change was made to the Environmental Motives scale in order to make it more child-friendly. The change was to make it less abstract by focusing on "pollution"' instead of “environmental problems". This modification was made because we thought that children would be better able to understand the concept of pollution (a specific, concrete problem) rather than the all encompassing and abstract term, "environmental problems." The children were given the following prompt "people around the world are generally concerned about environmental problems because of the consequences that result from polluting the environment. However, people differ in the problems that concern them the most." And then the children were asked to " please rate each of the 
following items from 1 (not important) to 7 (very important) in response to the question. I am concerned about pollution because of the consequences for." 'In addition, the items were also modified. Egoistic concern items were: me, my future, my health, and my lifestyle $(\mathrm{a}=.89)$. Altruistic concern items were: children, future generations, humanity, and my family $(\mathrm{a}=.83)$. Biospheric concern items were: animals, birds, plants, and trees $(\mathrm{a}=.81)$. Chance, Bruni, and Schultz (2008) showed that the basic 3-factor structure held up when Confirmatory Factor analyses were conducted on the Children's Environmental Motives scale.

There were several unique items that were asked in the interview with the children. For instance, the children were asked how serious they thought environmental problems were in California and around the world. They also rated these statements: "I like being inside" and "I like being outside" on a five-point scale, from 1 (strongly disagree) to 5 (strongly agree). Finally, the children were asked to report the number of hours that they engaged in various activities on a typical weekday and in an average weekend day. These activities were: playing inside, playing outside, watching television, playing video games, reading, playing on the computer, sleeping, playing sports, playing a musical instrument, being at the beach/pool, being at the park/playground.

Implicit connectedness with nature were measured using a PC- version of FlexiTwins. The blocks and trials were identical to that used with adults in the previous two studies, except that children were randomly assigned to play the game with either pictures as stimuli or with words as stimuli. When the stimuli were pictures, the child's own picture was used for the Me category (taken using a web camera) and pictures of other children drawn from a data- base of pictures of children was used as stimuli for the Other category. The images of natural and built objects were hand-drawn color images. When the stimuli were words, the Me and Other categories were the same as those used in Studies 1 and 2. Finally, to assure accurate data from the participants, the children were asked to play FlexiTwins until they acquired two testing sessions with accuracy rates greater then $70 \%$. Reported results were based on the two testing sessions in which the child received the accuracy rates of greater than $70 \%$ correct. Only two children had to play the game three times before they generated accuracy rates greater than $70 \%$ correct.

\section{Procedure}

After obtaining signed informed consent from their parents, children completed the questionnaire individually. Children were then interviewed individually and they played FlexiTwins twice, randomly assigned to play with either pictures or words. Upon completion of the games, the children were debriefed and thanked.

\section{Study 3: results and discussion}

Complete data was obtained from 30 children. In this study, the extent to which children were able to play FlexiTwins using either pictures or words was also examined. This analysis showed that there was no significant difference in FlexiTwins' D-scores when using pictures $(M=.83, S D$ $=.33$ ) or words $(M=.66, S D=.38), t(28)=1.29, p=.21$. Given that no differences were found between FlexiTwins D-score with pictures or words, further analysis using FlexiTwins D-scores are from the combined data of both pictures and words. The children's D-scores on FlexiTwins ranged from -.16 to $1.62(M=.73, S D=.37)$. Approximately $96 \%$ of the children showed some degree of preference for natural associations and only one child had a negative D-score. The internal reliability of FlexiTwins was first examined by correlating the two subscales created by the game (D1 and D2). Surprisingly, the correlation between D1 $(M=.63, S D=.47)$ and D2 $(M=.83$, $S D=.47)$ was not significant at the initial testing $(r=.23, p=.23)$ nor at retest $(r=.10, p=.59)$. However, the test-retest using the full scores at the initial testing $(M=.73, S D=.37)$ was significantly 
correlated with FlexiTwins D-score at retest $(M=.64, S D=.37), r=.62, p<.01$.

Correlations were computed between implicit and explicit measures of environmental concern. No significant correlations were found between FlexiTwins D-score and explicit measures of environment concern (Inclusion of Nature in Self measure: $M=4.50, S D=1.61, r=-.02, p=.91$; environmental concern: $M=5.50, S D=1.46, r=.052, p=.79$; and environmental intent: $M=4.90$, $S D=2.91, r=.121, p=.52$ ). FlexiTwins $\mathrm{D}$-scores were also not significantly correlated with subscales of the Environmental Motives scale; however, the correlations were in the expected direction (Egoistic concern: $M=-.16, S D=.52, r=-.18, p=.36$; Altruistic concern: $M=-.07, S D$ $=.53, r=.23, p=.23$; and Biospheric concern: $M=.31, S D=.85, r=.16, p=.31$ ).

Next, demographic variables were examined. Results showed that boys $(M=.59, S D=.30)$ had significantly lower $\mathrm{D}$-scores than girls $(M=.89, S D=.38), t(28)=-2.38, p<.05$, suggesting that girls show a stronger implicit connection with nature than boys. Again, this is in line with prior studies showing that women show stronger associations with nature than do men (Schultz \& Tabanico, 2007). Regarding leisure activities, there was a significant negative correlation between the FlexiTwins D-score and the hours that the children reported watching television $(M=1.95, S D$ $=2.17)$ and playing video games $(M=1.68, S D=2.28)$ on an average weekend day (television: $r=-.41, p<.05$; video games: $r=-.45, p<.05$ ). In looking at the effect of hours spent playing indoors on preference for nature, two children were dropped from analysis for incorrectly completing the survey. Once these children were dropped from the analysis, there was a significant negative correlation between the FlexiTwins D-score and the hours children spent playing inside $(M=3.80, S D=2.14 ; r=-.36, p<.05)$. No significant correlations were found between the FlexiTwins D-score and the amount of time spent outside, reading, playing on the computer, sleeping, playing sports, playing musical instruments, going to the beach or pool, playing at the park or playground, or shopping. These correlations suggest that the activities that children participate in may be related to their development of environmental concern and connectedness with nature. We intend to further explore these relationships in our longitudinal study.

\section{General discussion}

Across all three studies we find evidence that FlexiTwins is a reliable and useful measure of implicit connectedness with nature. It can be a valuable tool for measuring implicit connections with nature among diverse samples, ranging from children to adults, cross-culturally, and in applied settings (e.g., schools, zoos). For instance, in Study 1 we found that FlexiTwins was a reliable measure for use with college students, in that it showed good internal reliability, testretest, and expected patterns of correlations with explicit measures of environmental concern and connectedness. Study 2 provides some evidence for validity using a known-groups sample of environmental activists. And finally, in Study 3, data collected from a group of students ages 10-12 suggested that FlexiTwins was usable with children, in that the scores were relatively stable across two successive administrations (test-retest).

We begin our discussion of the results by commenting on the psychometric properties of the FlexiTwins measure. Importantly, our findings should be viewed within the broader context of IAT research, which has attracted hundreds of publications since the measurement approach was introduced in 1998 (cf. Greenwald, Poehlman, Uhlmann, \& Banaji, 2009, for a meta-analysis of 122 research reports with combined samples of 14,900 participants). 
Our measure, FlexiTwins, incorporates the IAT architecture into a fun and usable game interface. Like the IAT more generally, the results reported in this paper show a consistent pattern of reliability in the FlexiTwins measure. Across all three studies, with diverse populations, we find a modest degree of internal reliability and test-retest reliability. For test-retest reliability, we find correlations of .42 for university students, .55 for environmental activists, and .62 for school children.

In addition to the reliability, we also find some evidence for the validity of the FlexiTwins measure. In Study 1, we found that the FlexiTwins D-score correlated in the expected direction with self- reported personal environmental concern $(r=.33)$, consideration of environmental impact in their daily lives $(r=.29)$, and the D-scores scores differentiated students who gave priority to environmental protection over economic growth $(d=.66)$. These correlations between implicit and explicit measures are consistent with other IAT research: in their meta-analysis Greenwald et al. (2009) report an aggregated implicit-explicit correlation of .36 across 151 samples. A second indication of validity comes from the known-groups comparisons reported in Study 2, where environmental activists were found to score higher on the FlexiTwins measure than did our sample of university students. At the implicit level, activists had an IAT-nature D-score of .62; children in Study 3 scored .73; and university students in Study 1 scored .44. For comparison, Schultz and Tabanico (2007) report IAT-nature D-scores of .40 for a sample of university students and .55 for a sample from the general public. Bruni et al. (2008) report IAT- nature Dscores of .48 for a sample of university students and .51 for a sample of visitors entering three NY zoos. Thus, taken together, the scores of both activists and children are higher than previouslyreported IAT-nature scores.

While our findings provide some evidence for the validity of the implicit connectedness with nature construct, there are several results that are not consistent with a valid measure. In Study 1 with university students, we found the expected pattern of correlations between the implicit and explicit measures. However, when looking at the correlations presented in Studies 2 and 3 with samples of activists and children, we find no significant correlations between the implicit and explicit measures. In fact, the reported explicit environment concerns of the activists and children were only moderate; whereas, the implicit environmental attitudes of these activists and children were relatively high. Although lack of expected correlations might call into question the validity of the measure, there are several alternative explanations.

One plausible explanation for the low implicit-explicit correlations is that there are fundamental differences between implicit and explicit attitudes. Several recent articles have suggested that implicit and explicit attitudes are related but distinct constructs (Lane, Banaji, Nosek, \& Greenwald, 2007; Nosek, 2007; Nosek \& Smyth, 2007). If implicit and explicit measures are tapping different constructs, then they therefore will not necessarily generate strong positive correlations. In addition, Rutland, Cameron, Milne, and McGeorge (2005) suggest that around the age of 10, the implicit and explicit attitudes of children begin to differ. Taken together, these findings suggest that implicit and explicit measures may tap distinct underlying constructs and therefore may not be consistently correlated (see also Olson et al., 2007). However, this explanation does not account for the significant implicit-explicit correlations found with our college student sample in Study 1 (and in prior studies with college students; see Schultz \& Tabanico, 2007). Importantly, the inconsistency in implicit-explicit correlations across samples is not unique to our work, and a considerable amount of basic psycho- logical research has explored this topic. While a definitive answer has not yet emerged, it seems clear that there are psychological and methodological variables that can moderate the strength of the relationship 
(Greenwald et al., 2009; Nosek \& Smyth, 2007). More work remains to be done on this topic. Another reason for the lack of a significant relationship between these implicit and explicit measures in Studies 2 and 3 could be the nature of the explicit measures we used. All of the explicit measures reported in this article were designed for use with adults (either college or general public) and have not been tested for use with children or environmental activists. Moreover, most of the explicit measures are focused on environmental concern, whereas FlexiTwins measures connectednessd that is, the strength of self- nature associations. Connectedness is not an attitude, but rather an aspect of self and self-construal. The differences in these measures (attitude versus self-construal) could account for the lack of a significant relationship between these measures. While theoretically we would predict that connectedness would be positively correlated with various measures of environmental concern, the test of these relationships is a test of our conceptual model and not necessarily a reflection on the psychometric properties of the measures.

Going beyond the psychometric properties, the IAT-nature measurement procedure continues to provide interesting and theoretically meaningful results. Not only has FlexiTwins demonstrated itself as a useful tool for research with diverse populations (e.g., children, activists, and college students), we also find it to be suitable for use outside of the laboratory. In the present studies, FlexiTwins was used in several applied settings: a classroom (Study

3) and over the internet (Studies 1 and 2). And, data presented from these studies is useful for beginning to understand how and why connectedness develops and the factors that promote or interfere with these cognitive associations. We hope the new game interface will facilitate research outside of the traditional laboratory testing environment and open up new research questions that can best be answered in real-world contexts. As an example, Bruni et al. (2008) report data using the FlexiTwins game on a handheld PocketPC device with samples obtained from NY City zoos.

One concern with moving IAT research into the field, or in porting the technique onto the web, is the increased noise that can occur during testing (e.g., variations in internet speed, computer specs, and environmental distracters). While no procedural controls were used in the present studies as would be in a traditional lab study, FlexiTwins was created with this in mind. Our intent was to create a fun and interesting testing interface that would keep participants focused on the task and thereby provide quality data. Our results show that we succeeded in this endeavor and that the data obtained from the game are comparable to those obtained using a more traditional testing procedure (e.g., E-prime, Inquisit, SuperLab). In data collected as part of the game development process, we found that scores produced using the traditional testing procedure (i.e., Inquisit) correlated significantly with scores produced using the game. ${ }^{1}$

From the three reported studies in this paper, we find that children have high connectedness with nature, both implicitly and explicitly, as did our sample of environmental activists. Yet at some point, some children lose their sense of connection with nature, as was seen in looking at our sample of college students. What is it that triggers this change? Is it some significant life experience, as suggested by Chawla $(1998,1999)$ and others (Palmer, 1993; Tanner, 1980)? Or perhaps it has to do with lifestyle, childhood experience, and family routine? Our research provides some initial support for this latter perspective. As we saw in Study 3, life experiences were correlated with implicit connectedness with nature. Of particular note are the findings that children who reported spending more time playing indoors $(r=-.36)$ had lower implicit connectedness with nature. Also, the amount of time spent watching TV $(r=-.41)$ 
or playing video games $(r=-.45)$ was negatively correlated with implicit connectedness with nature.

While the cross-sectional nature of the data limits any causal conclusions, several of the findings are relevant to recent speculations about the decline in outdoor play among children and the corresponding rise in use of technology (Louv, 2006). In the present studies, we do not find evidence for this effectd the correlations between implicit connectedness with nature and time spent playing outside were small and not statistically significant. Although our findings did not directly support Louv's hypothesis, Louv suggests that it is a lack of unstructured outdoor play that is missing from childhood experiences today. The children in our sample reported playing outside, but a high percentage of this time was spent in structured activities like sports or organized events, rather than unstructured play like roaming the woods, valleys, and gullies, or climbing trees. Thus, although reported time spent playing outdoors did not correlate with implicit connectedness with nature in our sample, our findings suggest that playing inside does not allow for a connection to be made.

In this paper, we have presented results from a new tool for measuring implicit associations. By incorporating the principles of the Implicit Association Test into a game interface, we are able to facilitate research with different populations. Across three studies, we find that FlexiTwins is a reliable and useful measure of implicit social cognition. Taken together, the results show generally high levels of implicit connectedness with nature, although the strength of the association is stronger in children and environmental activists, than college students. We hope that this new tool will facilitate substantive research about the origins and consequences of implicit connectedness with nature.

\section{Acknowledgements}

We want to acknowledge the intellectual support of Carol Saunders and the financial support of the Brookfield Zoo. Our appreciation also goes to Jeremy Bowlin, Randie C. Chance, Karelle A. Jones, and Wesley Mouw, for their help with the reported studies, and to Tom Crompton for his help with the data reported in Study 2.

Portions of this paper were presented at the 7th annual meeting of the Society for Personality and Social Psychology, Palm Springs, CA, 2006, the 86th annual meeting of the Western Psychological Association, Palm Springs, CA, and the 87th annual meeting of the Western Psychological Association, Vancouver, BC, 2007. 


\section{References}

Arnocky, S., Stroink, M., \& De Cicco, T. (2007). Self-construal predicts environmental concern, cooperation, and conservation. Journal of Environmental Psychology, 27, $255-264$.

Baron, S., \& Banaji, M. R. (2006). The development of implicit attitudes: evidence of race evaluations from ages 6, 10, and adulthood. Psychological Science, 17, 53-58.

Bruni, C. M., Fraser, J., \& Schultz, P. W. (2008). The value of zoo experiences for developing implicit connections with nature. Journal of Visitor Studies, 11, 1-12. Chance, R.

C., Bruni, C. M., \& Schultz, P. W. (2008, April). A modified Environmental Motives scale for use with children. Poster presented at the 88th annual meeting of the Western Psychological Association, Irvine, CA.

Chawla, L. (1998). Significant life experiences revisited: a review of research on sources of environmental sensitivity. Journal of Environmental Education, 29, 11-21.

Chawla, L. (1999). Life paths into effective environmental action. Journal of Environmental Education, 31, 15-26.

Clayton, S. (2003). Environmental identity: a conceptual and an operational defi- nition. In S. Clayton, \& S. Opotow (Eds.), Identity and the natural environment. Cambridge, MA: MIT Press.

Cunningham, W. A., Preacher, K. J., \& Banaji, M. (2001). Implicit attitude measures: consistency, stability, and convergent validity. Psychological Science, 12, 163-170. Department for Environment, Food and Rural Affairs (DEFRA). (2002). Survey of public attitudes to quality of life and to the environment: 2001. London. Available online at. Department of Environment Food \& Rural Affairs (www.defra.gov.uk).

Dunlap, R. E., Gallup, G., \& Gallup, A. (1992). Health of the planet: Results of a 1992 international environmental opinion survey of citizens in 24 countries. Princeton, NJ: The George H. Gallup International Institute.

Dunlap, R. E., Gallup, G., \& Gallup, A. (1993). Global environmental concern: results from an international pubic opinion survey. Environment, 35, 33-39.

Dunlap, R., Van Liere, K., Mertig, A., \& Jones, R. E. (2000). Measuring endorsement of the new ecological paradigm: a revised NEP scale. Journal of Social Issues, 56, 425442.

Dutcher, D. D., Finley, J. C., \& Luloff, A. E. (2007). Connectivity with nature as a measure of environmental values. Environment and Behavior, 39, 474-493.

Frantz, C. M., Mayer, F. S., Norton, C., \& Rock, M. (2005). There is no "I'” in nature: the influence of self-awareness on connectedness to nature. Journal of Environ- mental Psychology, 25, 425-436.

Greenwald, A. G., Banaji, M. R., Rudman, L. A., Farnham, S. D., Nosek, B. A., \& Mellot, D. S. (2002). A unified theory of implicit attitudes, stereotypes, self- esteem, and self-concept. Psychological Review, 109, 3-25.

Greenwald, A. G., McGhee, D. E., \& Schwartz, J. L. K. (1998). Measuring individual differences in implicit social cognition: the Implicit Association Test. Journal of Personality and Social Psychology, 74, 1464-1480.

Greenwald, A. G., Nosek, B. A., \& Banaji, M. R. (2003). Understanding and using the Implicit Association Test: I. An improved scoring algorithm. Journal of Person- ality and Social Psychology, 85, 197-216.

Greenwald, A. G., Poehlman, T. A., Uhlmann, E., \& Banaji, M. (2009). Understanding and using the Implicit Association Test: III. Meta-analysis of predictive validity. Journal of Personality and Social Psychology, 97, 17-41.

Kidner, D. (2001). Nature and psyche: Radical environmentalism and the politics of subjectivity. New York: State University of New York Press.

Lane, K. A., Banaji, M. R., Nosek, B. A., \& Greenwald, A. G. (2007). Understanding and using the Implicit Association Test: IV. What we know (so far) about the method. In B. 
Wittenbrink, \& N. Schwarz (Eds.), Implicit measures of attitudes: Procedures and controversies. New York: NY: The Guilford Press.

Louv, R. (2006). Last child in the woods: Saving our children from nature-deficit disorder. Chapel Hill, NC: Algonquin Books of Chapel Hill.

Mayer, F. S., \& Frantz, M. (2004). The connectedness to nature scale: a measure of individuals' feeling in community with nature. Journal of Environmental Psychology, 24, 503-515.

Milfont, T., Duckitt, J., \& Cameron, L. (2006). A cross-cultural study of environmental motive concerns and their implications for proenvironmental behavior. Envi- ronment and Behavior, 38, 745-767.

Nosek, B., \& Smyth, F. (2007). A multitrait-multimethod validation of the Implicit Association Test: implicit and explicit attitudes are related but distinct constructs. Experimental Psychology, 54, 14-29.

Nosek, B. A. (2007). Implicit-explicit relations. Current Direction in Psychological Science, 16, 65-69.

Nosek, B. A., \& Banaji, M. R. (2001). The go/no-go association task. Social Cognition, 19, 625-664.

Nosek, B. A., Greenwald, A. G., \& Banaji, M. R. (2007). The Implicit Association Test at age 7: a methodological and conceptual review. In J. A. Bargh (Ed.), Automatic processes in social thinking and behavior (pp. 265-292). Psychology Press.

Olson, M., Fazio, R., \& Hermann, A. (2007). Reporting tendencies underlie discrepancies between implicit and explicit measures of self-esteem. Psychological Science, 18, 287-291.

Palmer, J. (1993). Development of concern for the environment and formative experiences of educators. Journal of Environmental Education, 24, 26-30.

Pennisi, L. (2007). Connection to nature: Development of a measurement scale. Unpublished Dissertation, University of Florida.

Perkins, A., \& Forehand, M. (2006). Decomposing the implicit self-concept: the relative influence of semantic meaning and valence on attribute self-associa- tions. Social Cognition, 24, 387-408.

Rolston, H. (1988). Environmental ethics: Duties to and values in the natural world. Philadelphia: Temple University Press.

Rosenthal, R., \& Rosnow, R. L. (1984). Essentials of behavioral research: Methods and data analysis (2nd ed.). Boston, MA: McGraw-Hill.

Rutland, A., Cameron, L., Milne, A., \& McGeorge, P. (2005). Social norms and selfpresentation: children's implicit and explicit intergroup attitudes. Child Development, 76, 451-466.

Saad, L. (2003). Environmental concern down this earth day: economic woes may be the cause. Gallup Poll Tuesday Briefing, April 17, 26-28.

Schultz, P. W. (2000). Empathizing with nature: the effect of perspective taking on concern for environmental issues. Journal of Social Issues, 56, 391-406.

Schultz, P. W. (2001). Assessing the structure of environmental concern: concern for self, other people, and the biosphere. Journal of Environmental Psychology, 21, 1-13.

Schultz, P. W. (2002). Inclusion with nature: understanding the psychology of humannature interactions. In P. Schmuck, \& P. W. Schultz (Eds.), The psychology of sustainable development. Boston: MA: Kluwer Academic Publishers.

Schultz, P. W., \& Tabanico, J. J. (2007). Self, identity, and the natural environment. Journal of Applied Social Psychology, 37, 1219-1247.

Schultz, P. W., Shriver, C., Tabanico, J. J., \& Khazian, A. M. (2004). Implicit connec- tions with nature. Journal of Environmental Psychology, 24, 31-42.

Schultz, P. W., Tabanico, J. J., Nolan, J., Jarvis, C., Shabo, J., \& Shriver, C. (2005). Valence study 2. Unpublished manuscript, California State University, San Marcos.

Snelgar, R. S. (2006). Egoistic, altruistic, and biospheric environmental concerns: 
measurement and structure. Journal of Environmental Psychology, 26, 87-99. Stern, P. C. (2000). Toward a coherent theory of environmentally significant behavior. Journal of Social Issues, 56, 407-424.

Tanner, T. (1980). Significant life experiences. Journal of Environmental Education, 11, 20 24. 